\title{
X ve Y Kuşaklarının Kredi ve Borç Eğilimleri Analizi: Ordu İli Örneği (Credit and Debt Tendencies Analysis of X and Y Generations: Case of Ordu Province)
}

\author{
Yusuf AKER iD a Alper KARAVARDAR (iD b \\ a Giresun Üniversitesi, Sosyal Bilimler Enstitüsü, İşletme Bölümü, Giresun, Türkiye. yusuf_aker@yahoo.com \\ b Giresun Üniversitesi, İktisadi ve İdari Bilimler Fakültesi, İşletme Bölümü, Giresun, Türkiye. akaravardar@yahoo.com
}

\begin{tabular}{|c|c|}
\hline MAKALE BİLGİSİ & ÖZET \\
\hline Anahtar Kelimeler: & Amaç - Kuşaklar arası kredi ve borç eğilimlerinin araştırıldığı bu eserde, $X$ ve $Y$ kuşağının \\
\hline X Kuşağ 1 & bankalardan aldığı krediler çeşitli faktörlere göre analiz edilecektir. Çalışmada farklı zaman \\
\hline & aralığında doğmuş, büyümüş ve yaşamlarını sürdürmüş olan bu iki kuşağın aldıkları kredili ürün \\
\hline & ve hizmetlerde farklılaşıp farklılaşmadığı araştırılacaktır. Araştırmanın asıl amacı; bankalar veya \\
\hline Kredi Kayıt Bürosu & kredi veren diğer kuruluşlar tarafından kredi tahsis politikaları belirlenirken kuşaklar arası farklı \\
\hline Banka & tahsis politikaları uygulanmasının rasyonel olup olmayacağının incelen \\
\hline Findeks & $\begin{array}{l}\text { Yöntem - Araştırmada Ordu ilinde faaliyet gösteren özel bir bankaya } 1 \text { Ocak-31 Mart } 2020 \text { tarihleri } \\
\text { arasında bireysel kredi başvurusunda bulunan } 125 \text { X kuşağı, } 125 \text { Y kuşağı olmak üzere toplam } 250\end{array}$ \\
\hline $\begin{array}{l}\text { Gönderilme Tarihi } 1 \text { Mayıs } \\
2020\end{array}$ & $\begin{array}{l}\text { kişinin Kredi Kayıt Bürosu (KKB) verileri incelenerek SPSS Windows } 25.0 \text { programına aktarılacaktır. } \\
\text { X ve Y kuşaklarının finansal eğilimlerini gösteren veriler kurulan hipotezler aracilığıyla Mann } \\
\text { Whitney U test yöntemiyle analiz edilecektir. }\end{array}$ \\
\hline $\begin{array}{l}\text { Revizyon Tarihi } 1 \text { Temmuz } \\
2020\end{array}$ & $\begin{array}{l}\text { Bulgular - Ampirik sonuçlar banka ve kredi veren diğer kuruluşların } X \text { ve } Y \text { kuşağına farklılaşmış } \\
\text { kredi tahsis politikaları uvgulamasının rasyonel olmavacaŏını göstermektedir. Tüm faktörlerde }\end{array}$ \\
\hline Kabul Tarihi 10 Temmuz 2020 & $\begin{array}{l}\text { büyük oranda benzerlik gösteren bu iki kuşağa yönelik tek bir kredi tahsis politikası } \\
\text { uygulanmasını daha uygun olacağı kanaatindeyiz. }\end{array}$ \\
\hline $\begin{array}{l}\text { Makale Kategorisi: } \\
\text { Araştırma Makalesi }\end{array}$ & $\begin{array}{l}\text { Tartışma - Kuşak ayrımı yapmadan tek tip bir kredi tahsis politikası ile bireysel kredi verilmesinin } \\
\text { banka ve finans kurumlarına risk yönetimi ve operasyonel maliyetler açısından katkı sağlayacağı } \\
\text { kanaatindeyiz. }\end{array}$ \\
\hline
\end{tabular}

\begin{tabular}{|c|c|}
\hline ARTICLE INFO & ABSTRACT \\
\hline $\begin{array}{l}\text { Keywords: } \\
\text { X Generation } \\
\text { Y Generation } \\
\text { Public Credit Registry } \\
\text { Bank }\end{array}$ & $\begin{array}{l}\text { Purpose - In this paper, where intergenerational loan and debt trends are investigated, credits } \\
\text { received by } X \text { and } Y \text { generations from banks will be analyzed according to various factors. In the } \\
\text { study, it will be investigated whether these two generations that were born, grown up and lived in } \\
\text { different time intervals differed in the loans and services they received. The main purpose of the } \\
\text { research is to examine whether it is rational to apply different generational allocation policies to each } \\
\text { generation while determined credit allocation policies by banks or other lenders. }\end{array}$ \\
\hline $\begin{array}{l}\text { Received } 1 \text { May } 2020 \\
\text { Revised } 1 \text { July } 2020\end{array}$ & $\begin{array}{l}\text { Design/methodology/approach - In the research, the data of the Public Credit Registry (PCR) of a } \\
\text { total of } 250 \text { people, including } 125 \text { X generation and } 125 \text { Y generation, who applied to a private bank } \\
\text { operating in Ordu province between 1-Jan-2020 and 31-Mar- } 2020 \text { will be examined and transferred } \\
\text { to the SPSS Windows } 25.0 \text { program. Data showing the financial trends of the X and Y generations } \\
\text { will be analyzed by using the Mann Whitney U test method through determined hypotheses. }\end{array}$ \\
\hline Accepted 10 July 2020 & $\begin{array}{l}\text { Findings - Empirical results indicate that it is not rational to apply differentiated loan allocation } \\
\text { policies to the } \mathrm{X} \text { and } \mathrm{Y} \text { generations of banks and other lenders. We believe that it would be more } \\
\text { appropriate to apply a same credit allocation policy for these two generations, which are highly } \\
\text { similar in all factors. }\end{array}$ \\
\hline Research Article & $\begin{array}{l}\text { Discussion - We believe that giving retail loans with a uniform credit allocation policy without } \\
\text { making a generation distinction will contribute to banks and financial institutions in terms of risk } \\
\text { management and operational costs. }\end{array}$ \\
\hline
\end{tabular}




\section{GİRIŞ}

Toplumsal hayatta meydana gelen teknolojik, sosyolojik ve siyasi değişimler zamanla toplumların tutum, davranış, yaşam tarzları ve algılarını etkilemektedir. Her konjonktürel dalgalanma kendisine ait toplumsal bir kuşak oluşturmaktadır. Savaşlar, salgın hastalıklar ve ekonomik çöküntüler içinde bulunduğu toplumun dünyayı algılama ve harekete geçme dürtülerine şekil vermektedir. Bu değişimler sonucu oluşan zaman dilimlerinde yaşayan insanlar kendi kuşaklarını oluşturmuş olurlar. Her bir zaman dilimini oluşturan farklılıklar kuşaklar arası değişimi meydana getirmektedir. Kuşaklar arası farklılıklar her bireyin kendi kuşağının tutum ve davranışlarının etkisinde hareket etmesiyle oluşmaktadır.

Kuşaklar arası farklılıklar günümüz finans dünyasında yönetilmesi gereken konulardan birisi olarak karşımıza çıkmaktadır. Kuşaklara göre farklı tahsis politikaları belirlemek mi yoksa kuşak farkı gözetmeksizin tüm kesimlere aynı politikalar ile hizmet vermek mi daha rasyoneldir? Hangi kuşağa kredi vermek için hevesli olunmalı ya da yaş kredi vermek için ana belirleyici unsurlardan birisi olmalı mıdır? Bankacılık sektörü risk yönetimi açısından oldukça önemli olan bu soruların cevabını aramak son dönem finans kesiminin önemli gündem maddelerinden birisi olmuştur. Günlük hayatta $X$ ve $Y$ kuşağının sosyal yaşamda farklı davranış şekilleri gösterdiği gözlemlenebilmektedir. Örneğin; $X$ kuşağı ebeveynlerin çocuklarının eğitimi için usta veya öğretmenlerine hitaben söyledikleri "eti senin kemiği benim" anlayışının $Y$ kuşağı ebeveynlerde tam da destek bulamadığı görülmektedir. X kuşağı yetişme şartlarına göre normal kabul edilen bu durum, $Y$ kuşağında tersi bir eğilimle daha müdahaleci ebeveynler şeklinde karşımıza çıkabilmektedir. $X$ ve $Y$ kuşağının kredi ve borç eğilimlerinde de bu tür farklılıklar mevcut mudur? Bu çalışmada ana amacımız finans kesiminin kredi verirken kuşak farkı gözetmesinin doğru olup olmayacağı üzerine sınamalar yaparak bilimsel sonuçlara ulaşmak ve öneriler yapmaktır.

Çalışmamızda $X$ ve $Y$ kuşağı mensuplarının kredi ve borç durumları analiz edilmeye çalışılacaktır. Ordu ilinde faaliyette bulunan özel bir bankaya bireysel kredi başvurusunda bulunan $X$ ve $Y$ kuşağı bireylerinin KKB verileri içerik analizine göre değerlendirilecektir. Bu kuşakların bankalardaki kredibiliteleri, KKB skorları, borçluluk endeksleri, güncel gecikmeli ödeme durumları, toplam anapara borçları, aylık taksit tutarları, idari takip durumları, toplam kayıt sayıları ve altı aylık başvuru sayıları karşılaştırmalı olarak analiz edilecektir. X ve $Y$ kuşaklarının finansal eğilimlerini gösteren veriler kurulan hipotezler aracılığıyla SPSS Windows 25.0 programinda Mann Whitney U test yöntemiyle analiz edilecektir.

\section{LITERATÜR TARAMASI}

Literatürde $X$ ve $Y$ kuşağı üzerine çok sayıda araştırma olduğu görülmektedir. Kuşakların davranış tutum ve özelliklerinin araştırıldığı her bir çalışma ile farklı sonuçlara ulaşılmış ve her bir sonuç için davranış şekilleri geliştirilmeye çalışılmıştır.

Danışman ve Gündüz (2018:707), iki kuşağın dışarıdan kahvaltı satın almada davranışlarının farklışıp farklılaşmadığını incelemiştir. $X$ ve $Y$ kuşağına mensup yalnızca İstanbul ilinde yaşayan 432 kişinin anket yöntemi ile analiz edildiği bu çalışmada alışkanlık, marka bağlılı̆̆ı ve odaklık konularında kuşaklar arasında farklılıkların olduğu saptanmıştır.

Bayramoğlu (2018:15) ise iki kuşağı liderlik davranışları açısından incelemiştir. Çorum ilinde kamu ve özel sektörde görev yapan 173 kişinin incelendiği bu çalışmada iki kuşağın liderlik davranışları bakımından bir farklılık taşımadığı görülmüştür.

Yılmaz Esencan ve Özdil (2017:91), X ve Y kuşağı hemşirelerin mesleki bağlılık durumunu değerlendirmiştir. Kuşaklar arası farkın hemşirelik mesleğine bağlılık üzerindeki etkisini inceleyerek yeni atanacak hemşirelerin güçlendirilecek yönlerini saptamak amacıyla yapılan bu çalışmada 80 ebe ve hemşire ile 110 stajyer öğrenci incelenmiştir. Araştırma sonucunda X kuşağ 1 hemşirelerin mesleklerini daha fazla sevdikleri, $Y$ kuşağı hemşirelerin ise meslekten ayrılma niyetlerinin daha fazla olduğu saptanmıştır.

Göksel ve Güneş (2017:807) iki kuşağı örgütsel sessizlik davranışı bağlamında incelemiştir. Kamu ve özel sektörde çalışan 206 katılımcı ile yapılan çalışma sonucunda kuşaklar arası bir farklılık saptanmamış, bu iki kuşağa mensup çalışanların örgütlerinde sessiz kalmadıkları sonucuna ulaşılmıştır.

$X$ ve $Y$ kuşağının KKB verileri üzerinden kredi ve borç eğilimlerinin analiz edildiği bu çalışmada, KKB üzerine yapılan çalışmalar da incelenmiştir. Karadağ ve Selimler (2014:91), Türkiye'de asimetrik bilgiyi azaltmaya çalışan kurumları incelemiştir. Bu kurumlardan birisi olan KKB'nin ürün ve hizmetlerine yönelik tanıtıcı 
bilgiler vermişlerdir.

Hanedar (2019:50) yaptığı çalışma ile borç alanların kredi notlarının paylaşılmasının bankacılık sistemine katkılarını incelemiştir. 1995 yılında kurulan KKB'nin son derece önemli olduğu belirtilen çalışmada Türkiye'deki KKB'lerin etkisi, gelişmesi ve önemi üzerine incelemelerde bulunmuştur.

Cücük (2019:63) ise çalışmasında kredi teleplerinde istihbarat ve kredi skorlamanın karar verme sürecine etkisini incelemiştir. Çalışmada müşterilerin kredilendirilme sürecinde yapılacak çalışmalar hakkında açıklayıcı bilgiler verilmiş ve farklı kaynaklardan bilgi edinirken izlenebilecek yollara ışık tutulması amaçlanmıştır.

X ve Y kuşağı üzerine çok sayıda araştırma yapılmış olmasına ragmen, bu kuşakların kredi ve borç eğilimlerini analiz eden herhangi bir çalışmaya rastlanılmamıştır. Bu konu üzerinde daha önce bir araştırmaya rastlanılmamış olması, çalışmayı $X$ ve $Y$ kuşağı teorilerine ilişkin literatüre katkı sağlar nitelikte kılmaktadır.

\section{KUŞAKLAR ve KUŞAK ÇEŞİTLİLIĞ́̇}

Kuşak olgusu ile ilgili sınıflandırmalara baktığımızda genellikle yaş kavramına dayandığını görmekteyiz. Türk Dil Kurumu'na göre kuşak, aynı yılarda doğmuş, yaklaşık yirmi beş, otuz yıllık yaş kümelerini oluşturan, benzer ödevlerle yükümlü olmuş aynı çağın şartlarını taşıyan kimseler olarak tanımlanmıştır (https://sozluk.gov.tr/). Zemke, Raines ve Filipczak (2013:7) ise kuşağı, belirli zaman aralığında doğmuş, büyümüş ve yaşamlarını sürdürmüş bu dönemin özelliklerini taşıyan benzer görüş açısına sahip insan grupları olarak tanımlamışlardır.

Kuşak kavramı ilk olarak Alman Sosyolog Karl Mannheim'in (1952:388) "The problem of Generation" (Kuşakların Problemleri) adlı makalesinde incelenmiştir. Mannheim'e göre bir kuşağın varlığından söz edebilmek için beş unsurun bir araya gelmesi gerekmektedir. Bu unsurlar, süreç içerisinde yeni katılımcıların varlığı, eski katılımcıların sistematik olarak yok olması, kuşak üyelerinin zaman dilimiyle sınırlı olması, kültürel miras aktarımı için sürekli gerekliliklerin olması ve kuşaklararası geçişin kesintisiz, devamlı bir süreç olması şeklinde özetlenmiştir.

Literatürde kuşakların gruplara ayrılmasında tam bir uzlaşı olmamakla birlikte keskin farklılıklar da bulunmamaktadır. Tablo 1'de kronolojik olarak bazı yazarların kuşak gruplamaları gösterilmiştir. Zemke vd., (2013:38) şu anda yaşayan 5 kuşak mevcut olup her bir kuşağın değerleri çocukluk ve gençlik deneyimleriyle şekillenmiştir.

\subsection{Sessiz Kuşak (1900 - 1944)}

1900-1945 yılları arasında doğan kişilerin oluşturduğu, dünyada büyük buhran, ekonomik kriz, II. Dünya Savaşı, Türkiye'de ise yeni cumhuriyetin kurulması, kurtuluş savaşı gibi zor hadiselerin yaşandığı bir dönemdir. Bu kuşağın çocukluk ve gençliği ekonomik ve sosyal olarak zor hadiselerle doludur (Reeves ve Oh, 2008:296 ; Zemke vd., 2013; Bolton vd., 2013:249).

Tablo 1. Kaynaklara Göre Kuşakların Sınıflandırılması

\begin{tabular}{|l|l|l|l|l|l|l|}
\hline Yazarlar & Yıl & $\begin{array}{l}\text { Sessiz } \\
\text { Kuşak }\end{array}$ & $\begin{array}{l}\text { Patlama Kuşağ1 } \\
\text { (Baby } \\
\text { Boomers) }\end{array}$ & X Kuşağ1 & Y Kuşağı & $\begin{array}{l}\text { Z Kuşağ1 } \\
\text { (Dijital } \\
\text { Nesil) }\end{array}$ \\
\hline Howe ve Strauss & 2000 & $1925-1943$ & $1943-1960$ & $1961-1981$ & $1982-2000$ & $2001-$ \\
\hline Zemke ve arkadaşları & 2000 & $1922-1943$ & $1944-1960$ & $1961-1980$ & $1981-1999$ & $2000-$ \\
\hline Washburn & 2000 & $1926-1945$ & $1945-1964$ & $1965-1981$ & $1982-2003$ & $2003-$ \\
\hline Lancaster ve Stillman & 2002 & $1900-1945$ & $1946-1964$ & $1965-1980$ & $1981-1999$ & $1999-$ \\
\hline Kyles & 2005 & $1900-1945$ & $1946-1964$ & $1965-1979$ & $1980-1999$ & $1999-$ \\
\hline Fleschner & 2007 & $1925-1945$ & $1946-1964$ & $1965-1980$ & $1981-2000$ & $2000-$ \\
\hline Trower & 2009 & $1925-1945$ & $1946-1964$ & $1965-1980$ & $1981-2000$ & $2000-$ \\
\hline Twenge ve arkadaşları & 2010 & $1925-1945$ & $1946-1964$ & $1965-1980$ & $1980-2000$ & $2000-$ \\
\hline Williams ve Page & 2011 & $1930-1945$ & $1946-1964$ & $1965-1976$ & $1977-1994$ & $1994-$ \\
\hline Berk & 2013 & -1946 & $1947-1965$ & $1966-1981$ & $1982-1996$ & $1996-$ \\
\hline
\end{tabular}

Kaynak: Şenturan vd.,(2016:173) ile Mücevher ve Erdem., (2018:62)'den derlenmiştir. 


\subsection{Patlama Kuşağı (Baby Boomers) (1944 - 1960)}

İkinci Dünya Savaşı'ndan hemen sonra oluşan ve sayısı 1 milyarı aşan çocuk doğumlarından dolayı bu kuşağa "Baby Boomers" kuşağı adı verilmiştir. Dünya' da insan hakları, Türkiye' de ise tek partili sistemden çok partili hayata geçiş çalışmalarının yapıldı̆̆ı döneme denk gelmektedir (Keleş, 2011, Hobart, 2015). Kuşak bireyleri rekabetçi ve işkolik olarak tanımlanabilir. Zorlu hayat şartlarında yetiştiklerinden iş hayatında değişime kapalı ve yeniliğe soğuk bakan bireylerdir. Bu kuşak kadın erkek eşitliği, ırkçılıkla mücadele ve çevre duyarlılığ1 konuları ile mücadele etmiştir (Strauss ve Howe, 1991:335 ; Delahoyde, 2009:171).

\subsection{Kuşağı (1961 - 1980)}

Bebek patlamasını takip eden bu kuşak, Dünya genelinde Berlin duvarının yıkılması, petrol krizi, Türkiye genelinde ise radyo ve televizyonların eve girmesi, sağ-sol çatışmaları gibi tarihsel olaylara tanıklık etmiştir. Bu dönemde eğitime çok önem verilmiş, teknoloji ile de çok sonradan tanışılmıştır. Finansal sorumlukları çok erken yaşlarda üstlenen bu kuşak üyeleri, yetişkinliğe erken adım atarak aile sorumluluğunu üzerlerine almışlardır. Teknolojinin çok hızlı geliştiği bu dönem bir geçiş kuşağı olma özelliği taşımaktadır. Teknolojik ürün kullanmada çok başarılı olamamalarına rağmen, ürünlerin çoğu bu kuşak üyeleri tarafından geliştirilmiştir. Ekonomik ve sosyal krizlerden dolayı kayıp kuşak olarak da adlandırılmaktadır (Toruntay, 2011:72 ; Altuntuğ, 2012:206).

\subsection{Y Kuşağı (1981-1999)}

Küreselleşmenin etkilerinin iyice hissedildiği, Irak savaşı, doğal afetler ve terör olaylarının yaşandığı, dijital kameralar, internet, MSN ve cep telefonlarının tüm dünyada yaygın hale geldiği dönemin kuşağıdır. Her şeyi sorgulayan Y kuşağı bireyleri teknolojiye meraklıdırlar. Teknoloji ve bilgisayar hayatlarının bir parçası haline gelmiştir (Mücevher ve Erdem, 2018). Özgürlüklerine düşkün olan bu kuşak üyeleri gezmeyi seven ve rahat yaşam şartlarının oluşmasına çok önem veren kişilerden oluşmaktadır (Adıgüzel vd., 2014:174).

\subsection{Z Kuşağı (2000 ve Sonrası)}

Farklı aile yapıları ve çeşitli etnik gruplar ile beraber büyüyen Z kuşağının 2020 yılından itibaren dünyanın en büyük tüketici grubu olması beklenmektedir. Bu kuşağın beklentileri sadece teknolojik olgularla sınırlı değildir. Dijital çocuklar olarak da nitelenen bu kuşak, uygulamalı ve doğrudan öğrenme yöntemlerine meyillidir. Yüzde 97 oranı ile Youtube'a kayıtlı olan bu kuşak üyelerinin iş dünyasında da çabuk sıkılıp kolay vazgeçebilme potansiyelleri çok yüksektir. Sınırsız bilgiye ulaşım ile bu kuşağın daha özgüvenli ve kariyer odaklı bir kuşak olacağı öngörülmektedir. Ayrıca İnternet kuşağı olarak da adlandırılan bu kuşak üyelerinin ortalama yaşam sürelerinin teknoloji sayesinde daha yüksek olacağı tahmin edilmektedir (eğitimpedia.com).

\section{KREDİ KAYIT BÜROSU}

Türkiye'deki bankacılık sektörü bireysel kredi pazarı özellikle 1990'lı yıllardan itibaren hızla büyümeye başlamış, sektöre "Müşteri İlişkileri Yönetimi" ve "Kredi Risk Yönetimi" gibi kavramlar girmiştir. Büyüyen bireysel kredi portföy hacmi bankaları kredi riskini doğru ölçmeye yönelik yöntemler bulmaya zorlamıştır. Aynı zamanda hızla gelişen yapay zeka algoritmaları ile de bankalar otomasyon süreçlerini yeniden dizayn etmeye çalışmışlardır. Bu durum bankaları işbirliğine itmiş, müşterilerin geçmiş kredi tarihçelerinin paylaşılması gerekliliğini ortaya çıkarmıştır. Bu ihtiyacı karşılamak amacıyla 1995'de dokuz bankanın ortaklığı ile Kredi Kayıt Bürosu (KKB) kurulmuştur (www.odd.org.tr).

Bankaların en önemli fonksiyonu topladıkları fonları krediye dönüştürmektir. Ancak kredi kullanacak müşterilerinin diğer bankalardaki durumlarını bilmeleri, kredi riskini yönetme açısından çok önemlidir. Risklerin iyi yönetilememesi sadece bankaları olumsuz etkilemekle kalmayıp ülke ekonomileri açısından azalan yatırımlara ve de büyüme üzerinde olumsuz etkiye neden olacaktır (www.odd.org.tr).

KKB'nin üye sayısı gün geçtikçe artmıştır. 2011 yılında yayınlanan kanun ve kanuna dayalı ek maddeler ile Türkiye Bankalar Birliği (TBB) nezdinde Risk Merkezi (RM) kurulmuştur. 2017 yıl sonu itibariyle, 44 banka, 61 faktöring, 43 leasing, 4 sigorta, 7 varlık yönetim şirketi, 14 tüketici finansman şirketi ile 3'ü de diğer olmak üzere toplam üye sayısı 156'ya ulaşmıştır. Bugün itibari ile KKB, 180 RM üyesi kuruluşa veri toplama ve paylaşım hizmeti vermektedir (kkb.gov.tr). 


\section{Kredi Kayıt Bürosu Kronolojisi}

- 1995 KKB Kuruldu.

- 1999 Kredi Referans Sistemi (KRS) hayata geçirildi.

- 2001 Kredi hesap kayıtları ile kredi başvuru kayıtları paylaşıma açıldı.

- 2002 Bilgi Doğrulama Sistemi hayata geçirildi.

- 2004 Bireysel Kredi Notu hayata geçirildi.

- 2005 Kurumsal Büro Sistemi hayata geçirildi.

- 2006 Limit Kontrol Sistemi uygulamaya alındi.

- 2007 İnternet Sahtekarlıkları Alarm Sistemi hayata geçirildi.

- 2009 Karş1lıssız Çek Sorgulama Sistemi kuruldu.

- 2013 Ticari Kredi Not Sistemi hayata geçirildi.

- 2014 Teminat Mektubu Durum Sorgulama hayata geçirildi.

- 2015 Findeks Karekodlu Çek Sistemi faaliyete geçti.

- 2017 Karekodlu Çek Uygulaması zorunlu hale geldi.

- 2018 Yabancı Para Kredi ve Gelir Doğrulama Projesi hayata geçirildi ww.kkb.com.tr).

\subsection{Bireysel KKB Raporu}

Bireysel KKB raporu bankalardan bireysel kredi ve kredi kartı alan bireylerin aldıkları kredi anapara miktarlarını, tüketici kredisi aylık ödeme tutarlarını, toplam kayıt sayılarını, güncel gecikmiş borçlarını, 6 aylık başvuru sayılarını, idari veya kanuni takibe uğrayıp uğramadıklarını ve tüm bu bilgilerin 1şığında belli kıstaslara göre oluşturulan bireysel kredi notunu göstermektedir. Bankalar ve kredi veren diğer kuruluşlar, KKB incelemesi sonucu ilgili bireylerin kredi almaya uygun olup olmadıklarını analiz edebilmektedirler. Uygulamalara baktığımızda bankalar KKB raporuna ek olarak bireylerden gelir bilgilerinin de teyidini isteyebilmektedirler. Ancak KKB raporu skoru belli kriterlerin altında olan bireylerde gelir belgesi de istemeden kredi başvuruları reddedilebilmektedir (kkb.gov.tr).

\subsubsection{Borçluluk Endeksi}

Skor bazlı bir endeks olan borçluluk endeksi ödeme güçlüğü yaşamayan ancak gelecek dönemlerde borcunu aşan bir ödeme yükü altına girebilecek kişileri önceden tespit etmeyi hedeflemektedir. Bu endeks ile ileriye yönelik aşırı borçlanma hızı tespit edilmeye çalışılır. Bu endeks mevcut borçlarını geciktirmeden ödeyen ancak sürekli ve yeni kredi kullanarak borç yükünü artıran kişileri temsil eden katsayı puanlı bir endeksidir.

\subsubsection{Toplam Kayıt Sayısı}

Banka veya üye finansal kurumlardan kaç adet kredili ürün satın alındığını gösteren bir kayıttır. Müşteri toplam kayıt sayısı kredi verenler açısından bir gösterge olarak değerlendirilmektedir.

\subsubsection{Toplam Ana Borcu / Bakiye}

Tüm bankalara olan toplam anapara borcunu bakiye olarak gösteren bir kayıttır. Kişinin borç yükünün tespit edilmesi açısından oldukça önemli bir göstergedir.

\subsubsection{Aylık Ödeme Tutarı}

$\mathrm{Bu}$ gösterge ise bireylerin kredi kartı veya kredili mevduat hesaplarını kapsam dışı tutarak taksitli ödeme şeklinde aldıkları tüketici, araç veya konut kredilerinin aylık taksitlerinin toplamını göstermektedir. Bu sayede kişilerin aylık ödeyeceği taksitli kredilerinin toplam miktarı tespit edilebilmektedir.

\subsubsection{Güncel Gecikmiş Borç}

$\mathrm{Bu}$ veri bireylerin geçmiş dönemlerini incelemeden sadece son ay ödemelerinde gecikme olup olmadığını adetsel olarak bildirmektedir. Tüm ürünler 1 olarak hesaplanır. Örneğin 4 üründe gecikmeli ödeme varsa 4 olarak sistemde kodlanır. Son 1 aylık ödeme periyodunu takip etmektedir.

\subsubsection{Altı Aylık Başvuru Sayısı}

Riskli müşterileri tespit etmek amacıyla kullanılan önemli bir göstergedir. Altı ay içerisinde bankalara kaç adet kredi başvuru yapıldığını gösterir. Başvuru sayısı yüksek olan kişiler riskli kategoride değerlendirilmektedir. Başvuru sayısının yüksek olması ya bu bireylerin hiçbir finansal kurumdan kredi alamayıp bankaları tek tek gezdiğini göstermekte ya da bu göstergeyle farklı bankalardan aynı ya da yakın zaman dilimleri içerisinde 
krediler çekerek kötü niyetli bir yaklaşım sergileyeceği tahmin edilen (krediyi ödememek niyetiyle kredi talebinde bulunan) bireylerin tespit edilmesini sağlamaktadır.

\subsubsection{Kredi Kayıt Bürosu (Findex) Notu}

Bireylerin bankacılık sektöründeki kayıtlı kredi ödeme alışkanlıklarının özeti durumundaki bir göstergedir. 1 ile 1900 arasında değişmektedir. Not 1900'e yaklaştıkça risk seviyesi azalmaktadır. Findex notu aşağıdaki unsurlardan oluşmaktadır (kkb.com.tr);

- Yüzde 35 - Kredili ürün ödeme alışkanlığı,

- Yüzde 35 - Mevcut hesap ve borç durumu,

- Yüzde 10 - Kredi kullanım yoğunluğu,

- Yüzde 11 - Yeni kredili ürün açlışları,

- Yüzde 9 - Diğer unsurlar.

Bankalar ve kredi veren kuruluşlar açısından çok güçlü bir gösterge olup, bireylerin taahhüt ettiği ödemeyi yapıp yapamayacağı konusunda fikir vermektedir.

\subsection{8. İdari Takip Durumu}

Kredi kullanan kişilerin daha önce idari takibe girip girmediğini gösteren kayıttır. İdari takibe giriş için ödememe süresi 90 gündür. Bu süre içerisinde ödenmeyen krediler için idari takip süreci başlatılır. Daha önce idari takip sürecine girmiş kişiler için L kodu kullanılır. KKB, L kodunu geçmişe yönelik bir kayıt olarak tutar.

\section{METODOLOJI}

\subsection{Araştırmanın Amacı ve Önemi}

Bu çalışma ile bir bankadan bireysel kredi talebinde bulunan $X$ ve $Y$ kuşağının kredi ve borç eğilimleri analiz edilecektir. Bankalara bireysel kredi başvurusunda bulunan bireylerin başvurularını kuşaklara ayırarak incelemenin, sonuçlar üzerinde etkisinin olup olmayacağı araştırılacaktır. Araştırmanın asıl amacı; bankalar veya kredi veren diğer kuruluşlar tarafından kredi tahsis politikaları belirlenirken kuşaklar arası farklı tahsis politikaları uygulanmasının rasyonel olup olmayacağının incelenmesidir. Bu alanda yapılan ilk çalışma olma özelliği taşıyan bu eser ile banka veya bireysel kredi veren kuruluşlara önerilerde bulunulacaktır.

\subsection{Araştırmanın Varsayımları ve Kısıtları}

- Bu çalışma Ordu ilinde faaliyette bulunan özel bir banka şubesine bireysel kredi başvurusu yapan X ve Y kuşağı bireyleri kapsamaktadır.

- Araştırma 1 Ocak - 31 Mart 2020 tarihleri arasında yapılan başvurular ile sınırlıdır.

- Çalışmada Zemde vd.'nin kuşak yaş sınıflandırmaları kabul edilmiştir.

- Çalışmaya sadece bireysel kredi başvurusunda bulunan gerçek kişiler dahil edilmiştir. Ticari ve tüzel kişiler kapsam dişı tutulmuştur.

- Sessiz kuşaktan herhangi bir başvuru olmamıştır. Ayrıca bu kuşağın bulunduğu yaş, ilgili bankanın kredi verilebilecek üst yaş sınırının üstündedir.

- Baby Boomers kuşağından 19, Z kuşağından ise 7 başvuru yapılmıştır. Sayı düşüklüğü dolaysıyla bu kuşaklar inceleme dışı tutulmuştur.

- Herhangi bir bankadan KKB kaydı olmayan kişiler araştırma dışı tutulmuştur. Veri toplama döneminde 38 KKB puanı olmayan başvuru olduğu gözlemlenmiştir.

- Covid 19- Yeni Koronavirüs hastalı̆̆ından dolayı özellikle Mart ayı üçüncü haftasından itibaren yapılan kredi başvurularında günlük ortalama yüzde 90 oranında azalma gözlemlenmiştir.

- Araştırma Ordu sınırları içinde bulunan tek bir banka şubesinde gerçekleştirildiği için çalışmanın genelleme yapma iddiası bulunmamaktadır. Genelleme yapılabilmesi için daha geniş çaplı örneklemler üzerinde çalışılması gerekmektedir.

\subsection{Araştırmanın Soruları ve Hipotezler}

Araştırmada $X$ ve $Y$ kuşağına mensup bireylerin kredi ve borç eğilimlerinin birbirinden farklı olup olmadığı araştııılmaktadır. Ölçülmeye çalışılan bilgi, farklı zaman aralıklarında yaşamış ve farklı karakteristik özellikleri olan bu kuşakların bankalardan kullandıkları kredilerde farklılaşıp farklılaşmadığıdır. Diğer bir anlatımla bu araştırma ile bankalar veya kreditörlerin, kredi tahsis politikalarını belirlerken kuşak ayrımını dikkate almaları, risk yönetimi ve operasyonel maliyetleri açısından onlara bir fayda sağlayıp sağlamayacağı 
araştırılacaktır.

Araştırmanın Hipotezleri;

- $\quad H 10: X$ ve $Y$ kuşağı arasında KKB puanları açısından bir fark yoktur.

- $\quad H 20$ : $X$ ve $Y$ kuşağ 1 arasında borçluluk endeksine göre bir fark yoktur.

- $\quad H 30$ : $X$ ve $Y$ kuşağı arasında güncel gecikmeli ödeyen kişi sayısına göre bir fark yoktur.

- $\quad H 40$ : $X$ ve $Y$ kuşağ 1 arasında toplam anapara borçlarına göre bir fark yoktur.

- $\quad H 50$ : $X$ ve $Y$ kuşağı arasında aylık ödenecek taksit tutarlarına göre bir fark yoktur.

- $\quad H 60$ : X ve Y kuşağı arasında idari takip olup olmama durumlarına göre bir fark yoktur.

- $\quad H 70: X$ ve $Y$ kuşağı arasında toplam kayıt sayısına göre bir fark yoktur.

- $\quad H 80$ : $X$ ve $Y$ kuşağı arasında altı aylık başvuru sayısına göre bir fark yoktur.

\subsection{Veri Toplama ve Analiz Yöntemi}

Araştırmanın konusu ve amacına uygun olarak kuşakların KKB verileri içerik analizine tabi tutularak hipotezler ile sınanmıştır. Araştırmanın örneklemi 1 Ocak - 31 Mart 2020 tarihleri arasında Ordu ilinde faaliyet gösteren özel bir banka şubesine kredi başvurusunda bulunan $125 \mathrm{X}$ kuşağı ve $125 \mathrm{Y}$ kuşağı olmak üzere toplam 250 kişiden oluşmaktadır. 250 kişiye ait KKB verileri IBM SPSS 25.0 programı kullanılarak analiz edilmiştir.

Araştırmada kurulan hipotezlerin sınanması amacıyla öncelikle normal dağılım varsayımı test edilmiştir. Faktörlerine göre KKB verileri normal dağılım test istatistikleri Tablo 3'te sunulmuştur.

Tablo 3. Faktörlerine Göre Normal Dağılım Test İstatistikleri

\begin{tabular}{|c|c|c|c|c|c|c|}
\hline & \multicolumn{3}{|c|}{ Kolmogorov-Smirnov } & \multicolumn{3}{|c|}{ Shapiro-Wilk } \\
\hline & İstatistik & df & p & İstatistik & df & p \\
\hline KKB Skoru & 073 & 250 & 002 & 967 & 250 & 000 \\
\hline Borçluluk Endeksi & 193 & 250 & 000 & 826 & 250 & 000 \\
\hline Güncel Gecikmeli Ödeme & 399 & 250 & 000 & 633 & 250 & 000 \\
\hline Toplam Anapara Borcu & 248 & 250 & ,000 & 622 & 250 & 000 \\
\hline Aylık Öden.Taksit Tutarı & 227 & 250 & 000 & 749 & 250 & 000 \\
\hline İdari Takip Durumu & 518 & 250 & 000 & 405 & 250 & 000 \\
\hline Toplam Kayıt Sayısı & 117 & 250 & 000 & ,930 & 250 & 000 \\
\hline Altı Aylık Başvuru Sayısı & 201 & 250 & 000 & 752 & 250 & ,000 \\
\hline
\end{tabular}

Tabloda 3 'te görüldüğü gibi tüm araştırma konularında hesaplanan normal dağılım test istatistiği anlamlılık değeri 0.05 ten küçüktür. \%95 güven aralığında normal dağılıma uymayan çarpık dağılım söz konusudur. Normal dağılım varsayımı sağlanmadığı için parametrik olmayan testler ile farklılığın olup olmadığı incelenmiştir. Çünkü normal dağılım varsayımına sahip parametrik testler, normal dağılıma sahip olmayan veriler üzerinde kullanıldığında elde edilen sonuçların güvenilir olmayacağı bilinmektedir. Kuşaklar arası farklılığın incelenmesi için Mann Whitney $U$ testi kullanılmıştır. Bu test parametrik test varsayımlarını sağlamayan iki ayrı bağımsız gruptan aynı konuda elde edilen iki ortalamanın karşılaştırılması amacı ile kullanılmaktadır. Bindak (2014), Mann Whitney U testinin örneklemin seçildiği kitlelerin, normal dağılıma uyum varsayımı yapmadan, aynı kitlelerden gelen iki bağımsız örneklemin sıfır hipotezini test etmekte kullanıldığını belirtmiştir.

\section{BULGULAR}

\subsection{Demografik Bulgular}

KKB verilerine göre kredi başvurusunda bulunan kadınların erkeklere oranı yaklaşık 1/4 oranındadır. Başvuruların büyük kısmı erkeklerden oluşmakta olup $X$ kuşağında bu oran yüzde 80 iken, $Y$ kuşağında ise yüzde $74,4^{\prime}$ tür. 
Tablo 4. Demografik İstatistikler

\begin{tabular}{|c|c|c|c|c|c|}
\hline \multirow[b]{2}{*}{ Kuşaklar } & & & \multicolumn{2}{|c|}{ Cinsiyet } & \multirow[b]{2}{*}{ Toplam } \\
\hline & & & Kadın & Erkek & \\
\hline & X Kuşağ1 & $\mathrm{N}$ & 25 & 100 & 125 \\
\hline & & $\%$ Ort. & $20 \%$ & $80 \%$ & $100,0 \%$ \\
\hline & Y Kuşağ & $\mathrm{N}$ & 32 & 93 & 125 \\
\hline & & $\%$ Ort. & $25,6 \%$ & $74,4 \%$ & $100,0 \%$ \\
\hline
\end{tabular}

\subsection{Hipotezlerin Test Edilmesi}

Çalışmanın bu bölümünde hipotezlere ait bulgular incelenmiştir. Çalışmanın hipotezlerine ait tüm veriler Tablo 5'te sunulmuştur.

Tablo 5. Mann Whitney U Testi ve Analizi

\begin{tabular}{|c|c|c|c|c|c|}
\hline & Kuşak & $\mathbf{N}$ & Ort. & Z & $\mathbf{P}$ \\
\hline \multirow[t]{2}{*}{ KKB Skoru } & X Kuşağ1 & 125 & 1370,22 & \multirow[t]{2}{*}{$-1,772$} & \multirow{2}{*}{,076 } \\
\hline & $\bar{Y}$ Kuşağ & 125 & 1300,64 & & \\
\hline \multirow[t]{2}{*}{ Borçluluk Endeksi } & X Kuşağ1 & 125 & 10,05 & \multirow[t]{2}{*}{,- 683} & \multirow[t]{2}{*}{ 495 } \\
\hline & Y Kuşağ1 & 125 & 10,80 & & \\
\hline \multirow[t]{2}{*}{ Güncel Gecikmeli Ödeme } & X Kuşağı & 125 & 1,5840 & \multirow[t]{2}{*}{,- 824} & \multirow[t]{2}{*}{,410 } \\
\hline & Y Kuşağ1 & 125 & 1,6400 & & \\
\hline \multirow[t]{2}{*}{ Toplam Anapara Borcu } & $\underline{X}$ Kuşağ1 & 125 & $-38200,94$ & \multirow[t]{2}{*}{,- 664} & \multirow[t]{2}{*}{,507 } \\
\hline & $\bar{Y}$ Kuşağ & 125 & 29569,53 & & \\
\hline \multirow[t]{2}{*}{ Aylık Ödenecek Taksit Tutarı } & X Kuşağı & 125 & 1217,86 & \multirow[t]{2}{*}{,-- 428} & \multirow[t]{2}{*}{ 669 } \\
\hline & Y Kuşağ1 & 125 & $-950,74$ & & \\
\hline \multirow[t]{2}{*}{ İdari Takip Durumu } & X Kuşağ1 & 125 & 1,128 & \multirow[t]{2}{*}{,- 368} & \multirow[t]{2}{*}{, 713} \\
\hline & Y Kuşağı & 125 & 1,144 & & \\
\hline \multirow[t]{2}{*}{ Toplam Kayıt Sayısı } & X Kuşağ1 & 125 & 11,48 & \multirow[t]{2}{*}{$-2,212$} & \multirow[t]{2}{*}{, $027^{*}$} \\
\hline & Y Kuşağ1 & 125 & 9,82 & & \\
\hline \multirow[t]{2}{*}{ Altı Aylık Başvuru Sayısı } & X Kuşağı & 125 & 2,91 & \multirow[t]{2}{*}{$-3,377$} & \multirow[t]{2}{*}{, $001^{*}$} \\
\hline & Y Kuşağ1 & 125 & 5,47 & & \\
\hline
\end{tabular}

H10: $X$ ve $Y$ kuşağı arasında KKB puanları açısından bir fark yoktur.

Araştırmada $X$ ve $Y$ kuşağı arasında KKB puanları açısından istatistiksel olarak anlamlı bir fark yoktur $(\mathrm{MWU}(\mathrm{Z})=-1,722, \mathrm{p}=0,076)$. İki kuşak KKB puan ortalamaların birbirlerine yakın seyrettikleri görülmektedir. X kuşağı 1370,22 puan ortalamasına sahipken, Y kuşağ 1300,64 puan ortalamasına sahiptir.

H20: $X$ ve $Y$ kuşağı arasında borçluluk endeksine göre bir fark yoktur.

Araştırmada $X$ ve $Y$ kuşağı arasında borçluluk endeksi puanları açısından istatistiksel olarak anlamlı bir fark yoktur $(\mathrm{MWU}(\mathrm{Z})=-0,683, \mathrm{p}=0,495)$. İki kuşağın borçluluk endeksi ortalamalarına bakıldığında birbirlerine yakın bir seyirden bahsedebiliriz. X kuşağı 10,05 borçluluk endeksi ortalamasına sahipken, Y kuşağı 10,80 ortalamaya sahiptir.

H30: X ve Y kuşağı arasında güncel gecikmeli ödeyen kişi sayısına göre bir fark yoktur.

Gecikmeli ödeme durumunu analiz ettiğimizde ise, $X$ ve $Y$ kuşağı arasında gecikmeli ödeyen kişi sayısı açısından istatistiksel olarak anlamlı bir fark yoktur $(\mathrm{MWU}(\mathrm{Z})=-0,824, \mathrm{p}=0,410)$. Kuşaklar arası gecikmeli ödeme durumu açısından da birbirlerine yakın seyir söz konusudur.

H40: X ve $Y$ kuşağı arasında toplam anapara borçlarına göre bir fark yoktur.

Araştırmada $X$ ve $Y$ kuşağı arasında toplam anapara borçları açısından istatistiksel olarak anlamlı bir fark yoktur $(\mathrm{MWU}(\mathrm{Z})=-0,664, \mathrm{p}=0,507)$. $\mathrm{X}$ kuşağ 1 üyelerinin ortalama 38.200.-TL anapara borçları mevcut iken, $\mathrm{Y}$ kuşağı üyelerinin ise 29.569.TL anapara borçları mevcuttur. İki kuşakta nerdeyse eşit derecede borçlanmaya sahiptir.

H50: $X$ ve $Y$ kuşağı arasında aylık ödenecek taksit tutarlarına göre bir fark yoktur.

Araştırmada $X$ ve $Y$ kuşağı arasında aylık taksit tutarları açısından istatistiksel olarak anlamlı bir fark yoktur $(\mathrm{MWU}(\mathrm{Z})=-0,428, \mathrm{p}=0,669)$. $\mathrm{X}$ kuşağı üyelerinin ortalama ödeyecekleri aylık taksit tutarı 1.217.- TL iken $\mathrm{Y}$ 
kuşağı 950.- TL ödemektedir. Taksit tutarları birbirine oldukça yakındır.

H60: $X$ ve $Y$ kuşağı arasında idari takip olup olmama durumlarına göre bir fark yoktur.

Araştırmada $X$ ve $Y$ kuşağı arasında daha önce idari takip olup olmaması açısından istatistiksel olarak anlamlı bir fark yoktur $(\mathrm{MWU}(\mathrm{Z})=-0,368, \mathrm{p}=0,713)$. Kuşakların idari takip sayıları birbirlerine yakın seyretmiştir.

H70: $X$ ve $Y$ kuşakları arasında toplam kayıt sayısı açısından bir fark yoktur.

Araştırmada $X$ ve $Y$ kuşağı arasında toplam kayıt sayısı açısından istatistiksel olarak anlamlı bir fark vardır $(\mathrm{MWU}(\mathrm{Z})=-2,212, \mathrm{p}=0,027) . \mathrm{X}$ kuşağı aldığ $\mathrm{k}$ kredi ürünü (kredili mevduat, araç, konut, tüketici kredisi, kredi kartı) sayısı bakımından Y kuşağından farklılaşmıştır. Ortalama 11,48 kayıt sayısı ile X kuşağı, ortalama 9,82 kayıt sayılı Y kuşağından daha fazla kredili ürün kullanmıştır. Ancak farkın çok açık olmadığı görülmektedir. H80: $X$ ve $Y$ kuşakları arasında altı aylık başvuru sayısı açısından bir fark yoktur.

Araştırmada $X$ ve $Y$ kuşağı arasında altı aylık başvuru sayısı açısından istatistiksel olarak anlamlı bir fark vardır $(M W U(Z)=-3,377, p=0,001)$. Başvuru sayısında $Y$ kuşağının nerdeyse iki katı farklılaştığı anlaşılmaktadır. Daha genç ve dinamik olan bu jenerasyonun kredi almaya daha istekli olduğu görülmektedir. Ancak araştırmanın verileri incelendiğinde kredi almak için daha fazla istekli olunması sonuçların tümü üzerinde bir fark oluşturmamıştır. Çünkü kuşakların toplam anapara borçlarına bakıldığında birbirlerine yakın seyrettikleri yani iki kuşağında birbirlerine yakın tutarlarda borçlandıkları görülmektedir.

Tablo 6. Bağımsız Değişkenler Spearman Korelasyon Tablosu

\begin{tabular}{|c|c|c|c|c|c|c|c|}
\hline \multicolumn{2}{|c|}{ Bağımsız Değişkenler } & \multirow{2}{*}{\begin{tabular}{|l|} 
KKB Skoru \\
1,000 \\
\end{tabular}} & \multirow{2}{*}{\begin{tabular}{|l}
$\begin{array}{l}\text { Borçluluk } \\
\text { Endeksi }\end{array}$ \\
,$- 637^{* *}$ \\
\end{tabular}} & \multirow{2}{*}{$\begin{array}{l}\begin{array}{l}\text { Toplam } \\
\text { Kayıt } \\
\text { Sayı1 }\end{array} \\
-0,052 \\
\end{array}$} & \multirow{2}{*}{\begin{tabular}{|l}
$\begin{array}{l}\text { Toplam } \\
\text { Anapara } \\
\text { Borcu }\end{array}$ \\
$-0,099$ \\
\end{tabular}} & \multirow{2}{*}{\begin{tabular}{|l|}
$\begin{array}{l}\text { Aylık } \\
\text { Ödenecek } \\
\text { Taksit } \\
\text { Tutarı }\end{array}$ \\
$-0,097$ \\
\end{tabular}} & \multirow{2}{*}{$\begin{array}{l}\text { Altı Aylık } \\
\text { Başvuru } \\
\text { Sayıs }\end{array}$} \\
\hline KKB Skoru & $\begin{array}{l}\text { Korelasyon } \\
\text { Katsayisi }\end{array}$ & & & & & & \\
\hline & $\mathrm{P}$ & & 0,000 & 0,412 & 0,118 & 0,124 & 0,000 \\
\hline \multirow{2}{*}{$\begin{array}{l}\text { Borçluluk } \\
\text { Endeksi }\end{array}$} & $\begin{array}{l}\text { Korelasyon } \\
\text { Katsayısı } \\
\end{array}$ &,$- 637^{* *}$ & 1,000 & $262^{* *}$ & $462^{* *}$ & $298^{* *}$ & , $281^{* *}$ \\
\hline & $\mathrm{P}$ & 0,000 & & 0,000 & 0,000 & 0,000 & 0,000 \\
\hline \multirow{2}{*}{$\begin{array}{l}\text { Toplam } \\
\text { Kayıt } \\
\text { Sayıs1 }\end{array}$} & $\begin{array}{l}\text { Korelasyon } \\
\text { Katsayis1 } \\
\end{array}$ & $-0,052$ & ,262 & 1,000 &, $560^{* * *}$ & $451^{* *}$ & $303^{* *}$ \\
\hline & $\mathrm{P}$ & 0,412 & 0,000 & & 0,000 & 0,000 & 0,000 \\
\hline \multirow{2}{*}{$\begin{array}{l}\text { Toplam } \\
\text { Anapara } \\
\text { Borcu }\end{array}$} & $\begin{array}{l}\text { Korelasyon } \\
\text { Katsayis1 }\end{array}$ & $-0,099$ & , $462^{* *}$ &, $560^{* *}$ & 1,000 &, $754^{* *}$ & , 206 \\
\hline & $\mathrm{P}$ & 0,118 & 0,000 & 0,000 & & 0,000 & 0,001 \\
\hline \multirow{2}{*}{$\begin{array}{l}\text { Aylık } \\
\text { Ödenecek } \\
\text { Taksit } \\
\text { Tutarı }\end{array}$} & $\begin{array}{l}\text { Korelasyon } \\
\text { Katsayis1 }\end{array}$ & $-0,097$ & , 298 & $451^{* *}$ &, $754^{* * *}$ & 1,000 & , 272 \\
\hline & $\mathrm{P}$ & 0,124 & 0,000 & 0,000 & 0,000 & . & 0,000 \\
\hline \multirow{2}{*}{$\begin{array}{l}\text { Altı Aylık } \\
\text { Başvuru } \\
\text { Sayısı }\end{array}$} & $\begin{array}{l}\text { Korelasyon } \\
\text { Katsayis1 }\end{array}$ &,$- 233^{* *}$ &, $281^{* *}$ & $303^{* *}$ & $206^{* *}$ & , 272 & 1,000 \\
\hline & $\mathrm{P}$ & 0,000 & 0,000 & 0,000 & 0,001 & 0,000 & \\
\hline
\end{tabular}

** 0,01 anlamlılık düzeyini ifade etmektedir.

Korelasyon analizi iki ya da daha fazla değişken arasında ilişki olup olmadığını incelemek için yapılan bir analizdir. Değişkenler arası ilişkinin yönü ve büyüklüğü bu analiz ile öğrenilebilmektedir. Korelasyon katsayısı 0 ile 1 arasında bir değer almaktadır. Korelasyon değeri pozitif veya negatif olabilmektedir. Bu değerler ilişkinin aynı veya zıt yönlü olduğunu gösterebilmektedir. Eğer korelasyon katsayısı 0 ise değişkenler arasında bir ilişki mevcut değildir. 0 ile 0,2 arasında ise çok zayıf bir ilişki vardır. 0,2 ile 0,4 arası katsayı zayıf korelasyonu temsil ederken, 0,4 ile 0,6 arası katsayı ise orta korelasyonu temsil etmektedir. 0,8 ile 1 arası ise yüksek korelasyonu temsil etmektedir (Dizgil,2018).

Tablo 6' da en yüksek korelasyon ilişkisi Toplam anapara borcu ile aylık ödenecek taksit tutarı arasındadır. Bu iki bağımsız değişken arasında 0,754 pozitif yönlü ve anlamlı bir ilişki mevcuttur. İkinci en yüksek ilişki ise 0,637 KKB skoru ve borçluluk endeksi arasındadır. Bu iki değişken arasında da negatif yönlü ve anlamlı bir ilişki mevcuttur. KKB puanı arttıkça borçluluk endeksi azalmakta, KKB puanı azaldıkça borçluluk endeksi artmaktadır. 


\section{SONUÇ ve ÖNERİLER}

Kuşaklar arası kredi ve borç eğilimlerinin araştırılmaya çalışıldığı bu eserde, $X$ ve $Y$ kuşaklarının bankalardan aldıkları krediler çeşitli faktörlere göre analiz edilmiştir. Bu çalışmada farklı zaman aralığında doğmuş, büyümüş ve yaşamlarını sürdürmüş olan bu iki kuşağın aldıkları kredili ürün ve hizmetlerde farklılaşıp farklılaşmadığı araştııılmıştır. Çalışmadaki asıl amaç bankalar veya kredi veren diğer kuruluşlar tarafından kredi tahsis politikaları belirlenirken kuşaklar arası farklı politikalar uygulanmasının rasyonel olup olmayacağını incelemektir. Diğer bir anlatımla, bankalar veya kreditörlerin, kredi tahsis politikalarını belirlerken kuşak ayrımını dikkate almaları, risk yönetimi ve operasyonel maliyetleri yönetmek açısından onlara bir fayda sağlayıp sağlamadığının araştırılmasıdır.

$X$ ve $Y$ kuşağı üzerine çok sayıda araştırma yapılmış olmasına ragmen, bu kuşakların kredi ve borç eğilimlerini analiz eden herhangi bir çalışmaya rastlanılmamıştır. Bu konu üzerinde daha önce bir araştırmaya rastlanılmamış olması, çalışmayı $\mathrm{X}$ ve $\mathrm{Y}$ kuşağı teorilerine ilişkin literatüre katkı sağlar nitelikte kılmaktadır.

Çalışmamızda X ve Y kuşağı üyeleri, KKB verileri ışığında KKB notu, borçluluk endeksi, güncel gecikmeli ödeme yapan kişi sayısı, toplam anapara borçları, aylık taksit ödemeleri, idari takip duruları, toplam kayıt sayıları ve altı aylık başvuru sayıları faktörlerine göre analize tabi tutulmuştur. Kurulan hipotezlerle sınanan veriler sonucunda, iki kuşakta da farklılığın olmadığı, benzer eğilimler gösterdikleri görülmektedir. Araştırma süresinin kapsayan 3 ay boyunca nerdeyse iki kuşaktan da eşit sayıda başvuru alınmıştır. KKB skoru, borçluluk endeksi, güncel gecikmeli ödeyen kişi sayısı, toplam anapara borçları, taksit ödemeleri ve idari takip durumları açısından her iki kuşak verilerinin oldukça yakın hareket ettikleri görülmektedir.

Altı aylık başvuru sayısında Y kuşağının farklılaşması, daha genç ve girişimci bir kuşak olması ile açıklanabilir. Ancak buna karşın X kuşağının da toplam kayıt sayısında $\mathrm{Y}$ kuşağından farklılaştı̆̆ görülmektedir. Ancak bu iki farklılaşmanın birbirini dengelemesiyle iki kuşak arasında fark olmadığını söyleyebiliriz.

$\mathrm{Bu}$ çalışma ile Ordu ilinde faaliyet gösteren özel bir bankaya 1 Ocak-31 Mart tarihleri arasında kredi başvurusunda bulunan 125 X kuşağı, 125 Y kuşağı olmak üzere 250 kişinin KKB verileri incelenmiştir. Yapılan analizler ile banka ve kredi veren diğer kuruluşların $X$ ve $Y$ kuşağını ayırarak ayrı kredi tahsis politikaları oluşturmalarının rasyonel olmayacağı, tüm faktörlerde büyük oranda benzer hareket eğiliminde olan bu iki kuşağa yönelik tek bir kredi tahsis politikasının uygulanmasının daha uygun olacağı kanaatindeyiz. Kuşak ayrımı yapılmadan tek tip politika ile bireysel kredi verilmesi banka ve finans kurumlarına risk yönetimi ve operasyonel maliyetler açısından katkı sağlayacağı kanaatindeyiz.

\section{KAYNAKÇA}

Adıgüzel, O., Batur, Z.H. ve Ekşili, N., (2014). Kuşakların Değişen Yüzü ve Y Kuşağı ile Ortaya Çıkan Yeni Çalışma Tarzı: Mobil Yakalılar. Süleyman Demirel Üniversitesi Sosyal Bilimler Enstitüsü Dergisi, 19, 174.

Altuntuğ, N. (2012). Kuşaktan Kuşağa Tüketim Olgusu ve Geleceğin Tüketici Profili. Organizasyon ve Yönetim Bilimleri Dergisi, 4(1), 206.

Bayramoğlu, G. (2018). X ve Y Kuşağının Liderlik Davranışı Açısından Karşılaştırılması. Ege Akademik Bakıs, 18(1), 15-30. https://doi.org/10.21121/eab.2018132202

Bindak, R. (2014). Mann-Whitney U ile Student's T Testinin I.Tip Hata ve Güç Bakımından Karşılaştırılması: Monte Carlo Simülasyon Çalışması. Afyon Kocatepe Üniversitesi Fen ve Mühendislik Bilimleri Dergisi, 14, $5-11$.

Bolton, R. N., Parasuraman, A., Hoafnagels, A., Kabaday1, S., Gruber, T., Loureiro, Y. K., Migchels, N., \& Solnet, D. (2013). Understanding Generation Y and Their Use of Social Media: A Review and Research Agenda. Journal of Service Management, 24(3), 245-267.

Cücük, C. Ö. (2019). Kredi Taleplerinde İstihbarat ve Kredi Skorlamanın Karar Verme Süreçlerine Etkisi. Göller Bölgesi Aylık Hakemli Ekonomi ve Kültür Dergisi, 7(77), 63-71.

Danışman, A. Ş., \& Gündüz, Ş. (2018). X ve Y Kuşaklarının Dışarıdan Kahvaltı Satın Alma Davranış 
Farkl1lkkları. Atatürk Üniversitesi Sosyal Bilimler Enstitüsü Dergisi, 22, 707-728.

Delahoyde, T. M. (2009). Generational Differences in Baccalaurate Nursing, 171, (Yayımlanmamış Doktora Tezi). College of Saint Mary, United States. https://www.csm.edu/sites/default/files/Delahoyde.pdf (Erişim Tarihi: 17 Mayıs 2020)

Dizgil, E., (2018). Bist Ticaret Endeksinde Yer Alan Şirketlerin Springate Finansal Başarısızlık Modeli ile İncelenmesi. Bilecik Şeyh Edebali Üniversitesi Sosyal Bilimler Enstitüsü Dergisi, 2(3), 260.

Eğitimpedia.com. (2018), Bir Kuşağ1 Anlamak: Z Kuşağ1 Kimdir?, https://www.egitimpedia.com/bir-kusagianlamak-z-kusagi-kimdir/ (Erişim Tarihi: 25 Mart 2020).

Fox, A., (2011). Mixing İt Up. (Cover Story). HR Magazine, 56(5), 22-27. https://www.shrm.org/hrtoday/news/hr-magazine/pages/0511fox.aspx (Erişim Tarihi: 01 Nisan 2020).

Göksel, A., \& Güneş, G. (2017). Kuşaklar Arasi Farklılaşma: X ve Y Kuşaklarının Örgütsel Sessizlik Davranışı Bağlamında Analizi. Gazi Üniversitesi İktisadi ve İdari Bilimler Fakültesi Dergisi, 19(3), 807-828.

Hanedar, Y. (2019). Kredi Kurumları Arasında Bilgi Paylaşımı: Türk Finans Sektörü İçin Tavsiyeler. Journal of Chemical Information and Modeling, 1(1), 50-57. https://doi.org/10.1017/CBO9781107415324.004

Hobart, B. (2015). Understanding Generation Y: What You Need to Know About the Millennials, White Paper, www.PrincetonOne.com, file:///C:/Users/Hp/Desktop/xy\%20ku\%C5\%9Fa\%C4\%9F\%C4\%B1\%20makale/i\%C5\%9Fletme\%20ara $\% \mathrm{C} 5 \% 9 \mathrm{Ft} \% \mathrm{C} 4 \% \mathrm{~B} 1 \mathrm{rmalar} \% \mathrm{C} 4 \% \mathrm{~B} 1 \% 20$ literat\%C3\%BCr/what\%20you\%20need.pdf (Erişim Tarihi: 24 Mart 2020).

Karadağ, M. M., \& Selimler, H. (2014). Kredi Değerlendirme Sürecinde Asimetrik Bilgiyi Azaltmaya Yönelik Uygulamalar, Tespit ve Öneriler. Maliye Finans Yazıları, 1(101), 91-131. https://doi.org/10.33203/mfy.519248

Keleş, H. N. (2011). Y Kuşağı Çalışanlarının Motivasyon Profillerinin Belirlenmesine Yönelik Bir Araştırma, Organizasyon ve Yönetim Bilimleri Dergisi, 3(2), 129-139.

Mannheim, K., (1952). The Problem of Generation, The Psychoanalytic Review, 57(3), 378-404.

Mücevher, M. H., \& Erdem, R. (2018). X Kuşağı Akademisyenleri İle Y Kuşağı Öğrencilerinin Birbirlerine Karşı Algıları. Süleyman Demirel Üniversitesi Vizyoner Dergisi, 9(22), 60-74. https://doi.org/10.21076/vizyoner.391745

Reeves, T. C. ve Oh, E. (2008). Generational Differences, 296, https://www.researchgate.net/publication/283326729_Generational_differences (Erişim Tarihi: 16 Mayis 2020)

Strauss,W. ve Howe, N. (1991). Generations: The History of America's Future, 1584 to 2069, New York, Perennial, 335-336. https://doi.org/10.1177/153660069301400207

Şenturan, Ş., Köse, A., Dertli, E.M., Başak, S., Şentürk, N., (2016). X ve Y Kuşağı Yöneticilerin İş Değerleri Alg1S1 ve Farklılıkları Üzerine İnceleme, Business and Economic Reserach Journal, 7(3), 173.

Toruntay H. (2011). Takım Rolleri Çalışması: X ve Y Kuşă̆̆ Üzerinde Karşılaştırmalı Bir Araştırma. (Yüksek Lisans Tezi). İstanbul Üniversitesi Sosyal Bilimler Enstitüsü, İstanbul.,72.

Yılmaz Esencan, T., \& Özdil, H. (2017). X ve Y Kuşağındaki Hemşirelerin Mesleki Bağlllıklarının Değerlendirilmesi. Ege Üniversitesi Hemşirelik Fakültesi Dergisi, 33(3), 91-104.

Zemke, R., Raines, C., Filipczak., B. (2013). Generation at Work: Managing the Clash of Veterans, Boomers, Xers and Nexters in Your Workplace. New York. American Management Association.

www.odd.org.tr,

https://www.kkb.com.tr/mailing/KKBEBULTENCOMTR/mailing/subat15/kkbuyeler/ODDDergi.pdf (Erişim Tarihi: 25 Mart 2020). 